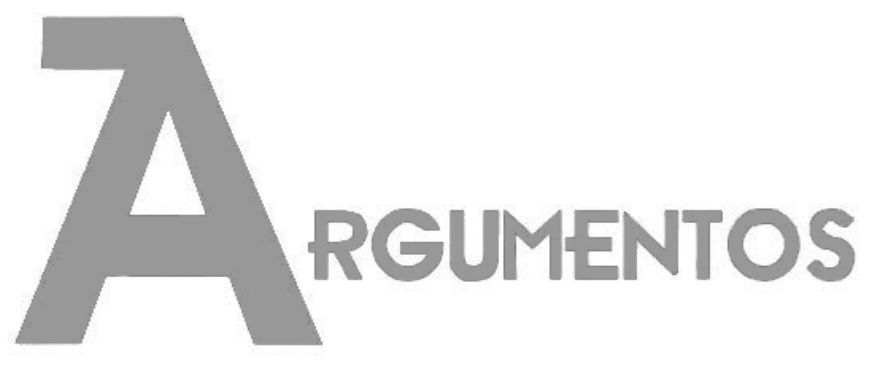

Vol. 17, n. 1, jan./jun. 2020 ISSN: 2527-2551 (online)

https://www.periodicos.unimontes.br/index.php/argumentos

\title{
Estado e meio ambiente: como concretizar um Estado de Direito Ambiental?
}

\author{
Chaiane Ferrazza Gomes ${ }^{1}$ \\ Lisianne Sabedra Ceolin² \\ Ronaldo Bernardino Colvero ${ }^{3}$
}

Recebido em: 19/09/2019

Aprovado em: 06/11/2019

Resumo: Este artigo tem por objetivo compreender o conceito de Estado de Direito Ambiental e, através de uma discussão teórica-conceitual, trazer alternativas para viabilizar a sua concretização. Antes disso, trouxe-se um breve resgate do papel do Estado perante o meio ambiente antes e após o advento da Constituição Federal de 1988 até se chegar ao conceito de Estado de Direito Ambiental. Constatou-se que, após décadas de omissão em relação meio ambiente, o Estado ensaia os primeiros passos rumo a um Estado considerado ambiental, porém também se percebe que o desafio é grande, mas as ações para concretizá-lo não são, apenas exigem mudanças de hábitos de cidadãos e governantes e a disponibilização de um processo de participação popular efetivo que ofereça um verdadeiro poder deliberativo aos cidadãos e os contemplem como sujeitos de vivências e experiências.

Palavras-chave: Estado. Meio ambiente. Estado de Direito Ambiental. Políticas Públicas. Políticas Públicas Ambientais.

\section{Estado y medio ambiente: cómo lograr un Estado de Derecho Ambiental?}

Resumen: Este artículo tiene como objetivo comprender el concepto de la ley del derecho ambiental $y$, a través de una discusión teórico-conceptual, ofrecer alternativas para hacerlo posible. Antes de esto, hubo un breve rescate del papel del estado en el medio ambiente antes

\footnotetext{
${ }^{1}$ Mestranda do Programa de Pós-Graduação em Políticas Públicas (PPGPP) da Universidade Federal do Pampa, Brasil. E-mail: chai_ferrazza@yahoo.com.br. ORCID: https://orcid.org/0000-0001-7304-490X.

2 Professora adjunta da Universidade Federal do Pampa - UNIPAMPA, Campus São Borja, Brasil. E-mail: lisianne.sabedra@gmail.comORCID: https://orcid.org/0000-0003-1369-0816.

3 Professor adjunto na Universidade Federal do Pampa, atuando no curso de Ciências Sociais - Ciência Política e Licenciatura em Ciências Humanas, atualmente professor do Pós-Graduação de Políticas Públicas da Universidade Federal do Pampa e do Pós-Graduação em Memória Social e Patrimônio da Universidade Federal de Pelotas, Brasil. E-mail: ronaldocolvero@unipampa.edu.br ORCID: https://orcid.org/0000-0003-2958-8656.
} 
Artigo | Estado e meio ambiente: como concretizar um Estado de Direito Ambiental? (GOMES, Chaiane Ferrazza; CEOLIN, Lisianne Sabedra; COLVERO, Ronaldo Bernardino)

y después de la llegada de la Constitución Federal de 1988 hasta que se llegó al concepto de Estado de Derecho Ambiental. Se descubrió que después de décadas de omisión en relación con el medio ambiente, el Estado está ensayando los primeros pasos hacia un estado considerado ambiental, pero también se percibe que el desafío es grande, pero las acciones para lograrlo no solo requieren cambios. de hábitos de ciudadanos y gobernantes y la disponibilidad de un proceso efectivo de participación popular que ofrezca un verdadero poder deliberativo a los ciudadanos y los contemple como sujetos de experiencias.

Palabras-clave: Estado. Medio ambiente. Estado del Derecho Ambiental. Políticas públicas. Políticas Públicas Ambientales.

\section{State and environment: how to achieve a State of Environmental Law?}

Abstract: This article aims to understand the concept of the State of Environmental Law and discuss about its implementation, suggesting ways for it to become reality. Prior to this, the State's role in the environment was brought back before and after the 1988 Constitution until the concept of the State of Environmental Law was reached. It was noticed that, after decades of omission in relation to the environment, the State is rehearsing the first steps towards a state considered environmental, but it is also perceived that the challenge is great, but the actions to achieve it are not, only require changes in habits of citizens and rulers and, therefore, demand access to information, collective awareness and public participation.

Keywords: State. Environment. State of Environmental Law. Public policy. Environmental Public Policies.

\section{Introdução}

Embora seja vasta a discussão sobre o termo meio ambiente e suas dimensões, aqui usaremos a concepção de Silva (1998, p. 2) que o define como "a interação do conjunto de elementos naturais, artificiais e culturais que propiciem o desenvolvimento equilibrado da vida em todas as suas formas", isso porque ele apresenta uma amplitude maior que àquela concebida pelo Plano Nacional de Meio Ambiente: "conjunto de definições, leis, influências, alterações e interações de ordem física, química e biológica, que permite, abriga e rege a vida em todas as suas formas" (BRASIL, 1981, p. 1). Assim, quando se menciona meio ambiente neste artigo refere-se ao conjunto de recursos naturais, artificiais e culturais, os quais são responsáveis por um desenvolvimento equilibrado da vida em todas as suas formas. Contudo, a prática demonstra-se muito desafiadora, pois esse desenvolvimento equilibrado encontra diversos obstáculos, dentre os quais o desmatamento ilegal, a poluição das águas, o depósito de resíduos sólidos em lugares inadequados, dentre outros.

Como afirma Benjamin (2010, p. 77), o meio ambiente "finalmente foi reconhecida pela Constituição brasileira de 1988, passados 488 anos da chegada dos portugueses ao Brasil". Essa afirmação foi trazida para demonstrar o lapso de tempo em 
Artigo | Estado e meio ambiente: como concretizar um Estado de Direito Ambiental? (GOMES, Chaiane Ferrazza; CEOLIN, Lisianne Sabedra; COLVERO, Ronaldo Bernardino)

que os recursos naturais do Brasil ficaram a mercê da proteção efetiva do Estado, pois embora nas décadas de 60, 70 tivessem tido atos do governo para regularizar algumas atividades relacionadas recursos naturais, tais como a criação do Estatuto da Terra e do Novo Código Florestal e, na década de 80, a Política Nacional do Meio Ambiente que trouxe toda a sistemática para a aplicação da política ambiental (conceitos básicos, objeto, princípios, objetivos, diretrizes, instrumentos, órgãos, responsabilidades objetiva, etc.), a tutela do Estado em relação ao meio ambiente só foi legitimada em 1988.

Frente a essa realidade que demonstra o longo período em que o Estado ficou sem expedir normas que contemplassem uma preocupação com a preservação dos recursos naturais, não é de causar espanto quando se fala que vivemos em uma Sociedade de Risco ${ }^{4}$. De acordo com Rodrigues, Fernandes e Philippi Jr. (2011, p. 397398), "o processo de industrialização conduziu o Brasil, a partir da década de 40, à formação de uma base industrial e de uma urbanização hoje considerada, pelas suas características, incompatível com o paradigma da sustentabilidade". Como bem afirmam os autores, a sustentabilidade ainda é considerada um paradigma na medida em que prevê a utilização dos recursos naturais de forma a não extingui-los.

Com a promulgação da Constituição de 1988, finalmente o meio ambiente foi elevado a direito fundamental, uma vez que a norma passa a estabelecer que cabe ao Estado, juntamente com a sociedade, a sua tutela. Desde então, passou-se a discutir um novo modelo de Estado pautado por uma maior preocupação com o meio ambiente frente à mercantilização através da conscientização do indivíduo e da coletividade, o qual se chama de Estado de Direito Ambiental. Porém, a concretização dessa construção teórica constitui-se no grande desafio do século XXI, na medida em que se são postos a frente os recursos naturais esgotáveis e o desenvolvimento econômico.

De posse desse cenário normativo que estabelece que a preservação do meio ambiente é um dever coletivo, ou seja, do Estado e da sociedade, este artigo tem por objetivo compreender o conceito de Estado de Direito Ambiental e discutir acerca da

\footnotetext{
4 "Uma fase do desenvolvimento da sociedade moderna, onde os riscos sociais, políticos, ecológicos e individuais, criados pelo momento da inovação, iludem cada vez mais as instituições de controle e proteção da sociedade industrial" (BECK, 2011, p. 28).
} 
Artigo | Estado e meio ambiente: como concretizar um Estado de Direito Ambiental? (GOMES, Chaiane Ferrazza; CEOLIN, Lisianne Sabedra; COLVERO, Ronaldo Bernardino)

sua concretização, trazendo para o debate estudiosos que abordam a temática, visando sugerir alternativas práticas para que ele possa tornar-se realidade.

Antes disso, trouxe-se um resgate do papel do Estado perante o meio ambiente antes e após a Constituição de 1988 até se chegar ao conceito de Estado de Direito Ambiental. Percebeu-se que, após décadas sem normativas mais incisivas no que toca ao dever de zelar pelo meio ambiente, o Estado ensaia os primeiros passos rumo a um Estado considerado ambiental com a promulgação da Carta Magna, porém também se percebe que o desafio é grande, mas as ações para concretizá-lo não são, apenas demandam mudanças de hábitos de cidadãos e governantes e de uma participação popular efetiva, a qual se efetiva com a disponibilização de informação clara e completa, com a organização dos indivíduos em grupos sociais, com enfoque no local, com a disponibilização de poder deliberativo aos indivíduos, dentre outros fatores.

\section{Estado e meio ambiente no Brasil}

De acordo com o O’Donnelll (2011), o Estado deve ser conceituado de três formas:

[primeiro como] entidade territorial que delimita quem são seus cidadãos (dãs) políticos (as); segundo como um sistema legal que promulga e respalda a atribuição dos direitos, liberdades e obrigações correspondentes, e terceiro [...] como um conjunto de burocracia-7s estatais que atuam em consonância básica com a efetividade desses direitos, liberdades e obrigações (O'DONNELL, 2011, p. 39).

Sendo assim, Estado seria um território que delimita quem são os indivíduos que estão submetidos a um conjunto de leis que emanam deveres e obrigações, as quais cabem a um conjunto de burocracias estatais executá-las e cobrá-las dos seus cidadãos. Já a concepção de Estado Moderno trazida por Schiera (1998) atribui dois novos elementos para entender o conceito de Estado: o poder e a administração de conflitos:

Trata-se de uma organização das relações sociais (poder) por meio de procedimentos técnicos preestabelecidos (instituições, administração), úteis para a prevenção e neutralização dos casos de conflito e para o alcance dos 
Artigo | Estado e meio ambiente: como concretizar um Estado de Direito Ambiental? (GOMES, Chaiane Ferrazza; CEOLIN, Lisianne Sabedra; COLVERO, Ronaldo Bernardino)

fins terrenos que as forças dominadoras na estrutura social reconhecem como próprias e impõem como gerais a todo o país (SCHIERA, 1998, p. 427).

Nessa concepção de Schiera (1998) são enfatizadas as relações de poder do Estado, concretizadas através de instituições que, com seus respectivos instrumentos administrativos, têm a função de fazer cumprir deveres e cobrar obrigações, visando prevenir e neutralizar possíveis conflitos dentro de uma estrutura social. Nesse sentido, Weber (1999, p. 526) afirma que o Estado "é uma relação de dominação de homens sobre homens, apoiada no meio da coação legítima (quer dizer, considerada legítima). Para que ele subsista, as pessoas dominadas têm que se submeterem à autoridade invocada pelas que dominam no momento dado". Isto é, indivíduos (detentores de cargos de poder) estabelecem normas e coagem os próprios indivíduos a fazerem cumprir tais normas.

Porém, esses indivíduos apenas se submetem a essas relações de poder e coerção, pois esperam em troca uma contrapartida do Estado, ou seja, esperam que os seus direitos individuais sejam garantidos. Essa é uma das concepções de Émile Durkheim sobre o Estado, conforme sintetiza Saccol (2012):

Para ele [Durkheim] um elemento essencial é que todo grupo político é a oposição entre governantes e governados, entre a autoridade e os que the são submetidos. Essas sociedades diferenciam-se das primitivas devido à proteção que é prestada aos seus membros. $O$ indivíduo pelo simples fato de nascer tem certos direitos que o Estado deve garantir. $O$ Estado é um organizador da vida social, sendo independente dela (SACCOL, 2012, p. 98).

Dessa forma, Estado pode ser entendido como um espaço territorial dotado de leis e instrumentos para que se possa fazer cumprir deveres e cobrar obrigações de seus indivíduos, exercendo poder coercitivo e administrando conflitos, ou seja, organizando a vida social. Porém, esses indivíduos apenas se submetem a esse poder coercitivo, pois esperam que seus direitos individuais sejam assegurados pelo Estado. E, dentre esses direitos, a partir da Constituição de 1988, está o de contar com um meio ambiente ecologicamente equilibrado, como está contido no Art. 225, da Carta Magna: "todos têm direito ao meio ambiente ecologicamente equilibrado, bem de uso comum do povo e essencial à sadia qualidade de vida" (BRASIL, 1988, p. 131). 
Artigo | Estado e meio ambiente: como concretizar um Estado de Direito Ambiental? (GOMES, Chaiane Ferrazza; CEOLIN, Lisianne Sabedra; COLVERO, Ronaldo Bernardino)

Oportunamente, a seguir será feito um resgate da relação do Estado com o meio ambiente ao longo do tempo, dividindo-o em antes e após a Constituição de 1988, com a pretensão de visualizar como o Estado conduziu as suas ações referentes à questão ambiental nesses dois períodos.

\section{Concepção de meio ambiente antes do advento da Constituição Federal de} 1988

Segundo Berté (2013, p. 145), no Primeiro Período Republicano ou Primeira República que compreendeu de 1889 a 1930, foi um período essencialmente de degradação ambiental caracterizado pelo: “crescimento e a ampla propagação do setor agrícola, preponderância de extensos latifúndios e predomínio do cultivo de um só produto (monocultura)". Segundo o autor, esse quadro apenas sofreu mudanças em 1930, com Revolução de 1930 que culminou o início do Segundo Período Republicano ou República Nova, momento no qual: "inúmeras mudanças políticas, sociais e econômicas foram introduzidas no país, o que representou um estímulo ao desenvolvimento industrial, embora o apoio de fato às indústrias de base só tenha sido fomentado a partir de 1937, com a institucionalização do Estado Novo" (BERTÉ, 2013, p. 145).

Berté (2013) afirma que em 1946 iniciou-se uma fase de desenvolvimento industrial, marcada por um programa de modernização industrial e urbana no Brasil, a qual adquiriu proporções maiores entre os anos 1951 e 1961:

É nesse cenário progressista que se insere o Governo de Juscelino Kubitschek (1956-1961), identificado pelo lema "Cinquenta anos de progresso em cinco anos de governo". No plano de desenvolvimento de seu governo, o chamado Plano de IMetas, constam como objetivos prioritários o desenvolvimento dos setores de energia, transporte, alimentação, indústria de base e educação (BERTÉ, 2013, p. 146).

O resultado desse cenário político e econômico foi a construção de estradas e de usinas hidrelétricas, criação da Superintendência do Desenvolvimento do Nordeste (Sudene), expansão do setor automobilístico e de eletrodomésticos e a criação da capital brasileira, Brasília, inaugurada em 1960. De acordo Berté (2013), esse período 
Artigo | Estado e meio ambiente: como concretizar um Estado de Direito Ambiental? (GOMES, Chaiane Ferrazza; CEOLIN, Lisianne Sabedra; COLVERO, Ronaldo Bernardino)

de mudanças no cenário brasileiro que se iniciou em 1960 e se estendeu até 1969, resultou nas primeiras importantes conquistas na área ambiental com a edição das seguintes leis:

- O Estatuto da Terra, pela Lei Federal n. 4504/1964 (Brasil, 1964), cujo objetivo foi "a execução da Reforma Agrária e a promoção de Política Agrícola", no qual consta a possibilidade de desapropriação de áreas para a implantação de reservas florestais;

- $\quad$ Novo Código Florestal, pela Lei Federal n. 4.771/1965 (Brasil, 1965b), que, entre outros aspectos, trata do desmatamento e da exploração das matas nativas;

- Política Nacional de Saneamento, que resultou de leis e decretos criados no período compreendido entre os anos de 1965 e 1969 e que, posteriormente, mais especificadamente em 1976, foi a base geradora do Programa Nacional de Saneamento (BERTÉ, 2013, p. 146, grifo do autor).

Nota-se, então, que o meio ambiente passou a entrar, de alguma forma, na agenda governamental a partir da década de 60. Essa preocupação com a normatização de atividades relacionadas ao meio ambiente nesse período, segundo Câmara e Oliveira (2011), também decorreu da influência de leis internacionais sobre o tema:

As manifestações protetivas avançaram das intenções manifestas no Direito Internacional para o âmbito interno dos mais diversos países. Assim, as Constituições posteriores a 1960 passaram a consagrá-las, impondo-se uma vigorosa atuação do Estado na esfera administrativa buscando conter a ocorrência de danos (CÂMARA; OLIVEIRA, 2011, p. 268).

Dessa forma, nota-se que o Brasil a partir da década de 60 , seguindo uma tendência internacional dos países em criar leis internas relacionadas à proteção ao meio ambiente, passou a ter uma maior atuação na esfera administrativa em relação à contenção de danos ambientais. Nesse contexto, segundo Muro Jr. (2016), a primeira Constituição brasileira a incluir o cuidado com o meio ambiente foi a de 1967, alterada pela Emenda Constitucional n. 1/1969, a qual trouxe no texto do Art. $72^{5}$ as primeiras preocupações com a questão ambiental: "muito singela, a Constituição de 1967 apenas

\footnotetext{
${ }^{5}$ A lei regulará, mediante prévio levantamento ecológico, o aproveitamento agrícola de terras sujeitas a intempéries e calamidades. 0 mau uso da terra impedirá o proprietário a receber incentivos e auxílios do Governo (BRASIL, 1967).
} 
Artigo | Estado e meio ambiente: como concretizar um Estado de Direito Ambiental? (GOMES, Chaiane Ferrazza; CEOLIN, Lisianne Sabedra; COLVERO, Ronaldo Bernardino)

mencionava a questão do levantamento ecológico e do aproveitamento agrícola em terras sujeitas a intempéries e a calamidades, sujeitando o proprietário rural à exclusão de incentivos estatais (MURO JR., 2016, p. 21)".

Benjamin (2010, p. 109) enfatiza que "é fato que, antes de 1988, as Constituições brasileiras não estavam desenhadas de modo a acomodar os valores e as preocupações próprios de um paradigma jurídico ecológico". Assim, percebe-se que o meio ambiente passou a ser uma prioridade do Estado no ordenamento jurídico, apenas após a promulgação da Constituição de 1988, sendo que antes disso o tema era tratado apenas de forma superficial.

Porém, como lembra Benjamin (2010), nesse período de "vazio constitucional", no que diz respeito ao cuidado com o meio ambiente, não significa que não houve a edição de normas com essa temática, mas sim que elas não abordaram de forma incisiva a tutela do meio ambiente: "a lacuna nas ordens constitucionais anteriores a 1988 não foi óbice sério e intransponível à regulamentação legal de controle das atividades nocivas ao ambiente ou, mais comumente, aos seus elementos" (BENJAMIN, 2010, p. 109). Isto é, por mais que as Constituições anteriores não trouxessem o meio ambiente como tutela do Estado, houve políticas públicas para regular as atividades, tais como o Estatuto da Terra, o Novo Código Florestal e a Política Nacional de Saneamento.

Entretanto, Muro Jr. (2016) considera que foi apenas na década de 70 que o Brasil passou a, de fato, a preocupar-se com as questões ambientais: "a mobilização do Estado brasileiro para normatizar o meio ambiente começou somente com a sua participação na Conferência de Estocolmo (1972), quando foi signatário do tratado internacional que levou o nome da cidade" (MURO JR., 2016, p. 21). Segundo Melo (2016), a Conferência de Estocolmo foi a primeira Conferência das Nações Unidas em escala mundial sobre as temáticas ambientais, da qual originou-se uma Declaração que, dentre outros princípios:

[...] encontra-se o conceito de responsabilidade para a proteção do meio ambiente e da conservação dos recursos naturais em relação às futuras gerações. É reconhecida a necessidade de introduzir a tutela ambiental nos programas de desenvolvimento e de adotar medidas integradas e coordenadas de administração dos recursos, de modo a assegurar que o desenvolvimento seja compatível com a necessidade de proteger e melhorar o ambiente (MELO, 2016, p. 242). 
Artigo | Estado e meio ambiente: como concretizar um Estado de Direito Ambiental? (GOMES, Chaiane Ferrazza; CEOLIN, Lisianne Sabedra; COLVERO, Ronaldo Bernardino)

Já na década de 80, foi editada a Lei n. 6.938, de 31 de agosto de 1981, a qual dispõe sobre a Política Nacional do Meio Ambiente (PNMA) e institui o Sistema Nacional do Meio Ambiente (SISNAMA), seus fins e mecanismos de formação e aplicação e dá outras providências. De acordo com Sirvinskas (2006, p. 103), o PNMA "trata-se da lei ambiental mais importante depois da Constituição Federal. Nela está traçada toda a sistemática necessária para a aplicação da política ambiental (conceitos básicos, objeto, princípios, objetivos, diretrizes, instrumentos, órgãos, responsabilidades objetiva, etc.)".

Portanto, mesmo que as Constituições anteriores a 1988 não tivessem dado um tratamento expresso de tutela ao meio ambiente, o Estado editou leis que, de alguma forma, contribuíram para a preservação do meio ambiente. Os atos do governo referentes à questão ambiental iniciaram-se na década de 60 , de forma sutil, com a edição de algumas leis para normatizar algumas atividades com potencial degradante ao meio ambiente, tais como o Estatuto da Terra (1964), Novo Código Florestal (1965) e a Política Nacional de Saneamento (1965 a 1969) e com a Constituição de 1967, a qual tratou de forma superficial a questão ambiental. Sendo, então, apenas nas décadas de 70 e 80 quando despontou a preocupação com a tutela do meio ambiente a partir da participação do Brasil na Conferência de Estocolmo e com a criação do PNMA, em 1981, quando "ensaiou-se o primeiro passo em direção a um paradigma jurídico-econômico que holisticamente tratasse e não maltratasse a terra, seus arvoredos e os processos ecológicos essências a elas associados" (BENJAMIN, 2010, p.77).

\section{A tutela ambiental à luz da Constituição Federal de 1988}

Foi a partir da promulgação da Constituição Federal de 1988 que o meio ambiente passou a ser tratado de forma preponderante normativamente: "com o advento da Constituição de 1988 ocorre um avanço significativo: o direito ao meio ambiente ecologicamente equilibrado é elevado a direito fundamental" (PIOVESAN; FACHIN, 2011, p. 36). Isso está preconizado no Art. 225, da Constituição Federal: "todos têm direito ao meio ambiente ecologicamente equilibrado, bem de uso comum do povo e essencial à sadia qualidade de vida, impondo-se ao poder público e à coletividade o 
Artigo | Estado e meio ambiente: como concretizar um Estado de Direito Ambiental? (GOMES, Chaiane Ferrazza; CEOLIN, Lisianne Sabedra; COLVERO, Ronaldo Bernardino)

dever de defendê-lo e preservá-lo para as presentes e futuras gerações (BRASIL, 1988, p. 2).

Assim, a partir da Constituição de 1988, o meio ambiente foi elevado a direito fundamental, trazendo o Estado para si a tutela do meio ambiente, porém não cabendo apenas a este o dever de protegê-lo e preservá-lo, mas também a todos os indivíduos. Além de "consagrar a proteção ambiental com um dos objetivos ou tarefas fundamentais do Estado - Socioambiental- de Direito brasileiro, sem prejuízo dos deveres fundamentais em matéria socioambiental" (SARLET; FENSTERSEIFER, 2010, p. 13).

Segundo Benjamin (2010, p. 89), a constitucionalização do meio ambiente trouxe consigo "benefícios variados e de diversas ordens, bens palpáveis, pelo impacto real que podem ter na (re) organização do relacionamento do ser humano com a natureza". O autor elenca seis benefícios substantivos da constitucionalização do meio ambiente, isto é, que reorganizam a estrutura profunda de direitos e deveres: 1) estabelecimento de um dever constitucional genérico de não degradar, base do regime de explorabilidade limitada e condicionada; 2) ecologização da propriedade e da sua função social; 3) a proteção ambiental como direito fundamental; 4) legitimação constitucional da função estatal reguladora; 5) redução da discricionariedade administrativa e 6) ampliação da participação pública.

Outro fato importante foi a Conferência das Nações Unidas sobre o ambiente e desenvolvimento (Unced) ocorrida no Rio de Janeiro, em 1992, conhecida por ECO 92. No evento, foram aprovados três documentos importantes: a Declaração do Rio sobre o ambiente e o desenvolvimento, a Declaração sobre "Princípios das florestas" e a Agenda 21, além disso foram adotadas duas importantes Convenções: a Convenção sobre a biodiversidade e a Convenção sobre as mudanças climáticas.

Sendo assim, é nítida a mudança de postura do Estado perante o meio ambiente após a promulgação da Constituição de 1988, na qual é posto que um meio ambiente saudável e equilibrado é um direito e um dever da coletividade. A partir dessa nova forma de tratar o meio ambiente, surge uma nova visão de Estado, conhecida como Estado de Direito Ambiental.

\section{Estado de Direito Ambiental}


Artigo | Estado e meio ambiente: como concretizar um Estado de Direito Ambiental? (GOMES, Chaiane Ferrazza; CEOLIN, Lisianne Sabedra; COLVERO, Ronaldo Bernardino)

De acordo com Leite (2010, p.169), "o Estado de Direito do Ambiente é uma construção teórica que se projeta no mundo real ainda como devir", na qual o Estado projeta no meio ambiente um papel preponderante em relação à mercantilização. Além disso, projeta na coletividade o dever e o direito de preservá-lo, como afirma Leite (2010), "o Estado Ambiental é um quadro de mais sociedade, mais direitos e deveres individuais e mais direitos e deveres coletivos e menos Estado e menos mercantilização (idem)".

Embora tenha essa preocupação com mais sociedade e menos Estado, o debate não gira em torno do público em detrimento do privado ou vice-versa, mas em torno de uma autonomia do indivíduo e da coletividade perante a mercantilização: "nesse novo contexto, não é prioritário o doseamento entre público e privado, mas sim o reforço da autonomia (logo, dos direitos e das responsabilidades) individual e social frente à mercantilização e à burocratização" (PUREZA; FRADE, 1998, p.8-9). Portanto, o Estado de Direito Ambiental tem como figuras centrais o indivíduo crítico e autônomo e o meio ambiente, cabendo ao Estado à tarefa de instigar essa consciência ecológica na coletividade através da disponibilização de informações, de educação ambiental e da promoção da participação popular, o que não significa que o Estado não detenha a tutela do meio ambiente, significa apenas que ele que abra mais espaço para a sociedade atuar conjuntamente na proteção e preservação do ambiente.

Nunes Júnior (2005, p. 3) faz uma diferenciação das finalidades de cada modelo de Estado para, então, esclarecer o objetivo do Estado Ambiental: "a finalidade do Estado Liberal é a liberdade, e a do Estado Social é a igualdade. Já o Estado Ambiental tem uma finalidade mais ampla: a solidariedade (centrada em valores que perpassam a esfera individualista própria do Estado Liberal)". Desse modo, o Estado de Direito Ambiental tem como finalidade a solidariedade, além de ter "valor como construção teórica e mérito como proposta de exploração de outras possibilidades que se apartam da realidade para compor novas combinações daquilo que existe" (LEITE, 2010, p. 169).

Para Canotilho (1999) para um Estado atribuir a condição de ambiental requer a priorização de duas dimensões jurídico-políticas importantes: 
Artigo | Estado e meio ambiente: como concretizar um Estado de Direito Ambiental? (GOMES, Chaiane Ferrazza; CEOLIN, Lisianne Sabedra; COLVERO, Ronaldo Bernardino)

A primeira é a obrigação de o Estado, em cooperação com outros Estados e cidadãos ou grupos da sociedade civil, promover políticas públicas (econômicas, educativas, de ordenamento) pautadas pelas exigências da sustentabilidade ecológica. A segunda relaciona-se com o dever de adopção de comportamentos públicos e privados amigos do ambiente de forma a dar expressão concreta à assumpção da responsabilidade dos poderes públicos perante as gerações futuras. [...] A afirmação desta nova dimensão do Estado pressupõe o diálogo democrático, exige instrumentos de participação, postula o princípio da cooperação com a sociedade civil. O Estado de ambiente constrói-se democraticamente de baixo para cima; não se dita em termos iluminísticos e autoritários de cima para baixo (CANOTILHO, 1999, p. 17).

Desse modo, tem-se que para um Estado "ser ambiental" é necessário que o mesmo esteja empenhado em criar políticas públicas relacionadas à economia, educação e de ordenamento pautadas pela exigência da sustentabilidade ecológica, além de adotar comportamentos que não agridam e venham a degradar o meio ambiente. Não obstante, essa concepção de Estado deve privilegiar o diálogo democrático com a sociedade, ou seja, o Estado de Direito Ambiental deve ser uma construção de baixo para cima, construída a partir da participação popular. Contudo, o desafio que se apresenta é como pôr em prática essas definições, ou seja, como materializá-las nas práticas cotidianas dos governantes e dos cidadãos para que o Estado de Direito Ambiental ultrapasse os limites do ordenamento jurídico e se materialize no cotidiano.

\section{O desafio da construção do Estado de Direito Ambiental}

Embora a proposta da construção de um Estado de Direito Ambiental traga consigo a esperança de uma sociedade mais consciente, crítica e predisposta a preservar o meio ambiente, ela constitui-se em um grande desafio na medida em que a preservação dos recursos ambientais é posta frente ao desenvolvimento econômico:

Diante de um mundo marcado por desigualdades sociais e pela degradação em escala planetária, construir um Estado de Direito Ambiental parece ser uma tarefa de difícil consecução, porque se sabe que os recursos ambientais são finitos e antagônicos com a produção de capital e consumo existentes (LEITE, 2010, p. 169). 
Artigo | Estado e meio ambiente: como concretizar um Estado de Direito Ambiental? (GOMES, Chaiane Ferrazza; CEOLIN, Lisianne Sabedra; COLVERO, Ronaldo Bernardino)

Reconhecido o tamanho e complexidade do desafio que é vivenciar na prática diária um Estado ambiental, torna-se pertinente buscar alternativas para concretizá-lo. Leite (2010, p. 181) acredita que, na prática, a execução de um Estado de Direito Ambiental "só será possível a partir da tomada de consciência global da crise ambiental, em face das exigências, sob pena de esgotamento irreversível dos recursos ambientais, de uma cidadania moderna, informada e pró-ativa".

Porém, Freitas (2010, p. 20) assinala que essa consciência da coletividade em relação ao seu papel pró-ativo na questão ambiental nem sempre existe. Isso resulta

que "na realidade, ao Poder Público que cabe o papel principal na tutela do ambiente sadio. De sua ação adequada e responsável deverá resultar, inclusive, efeito pedagógico ao atuar no sentido do fortalecimento da consciência ecológica do povo". Assim, embora a responsabilidade sobre o meio ambiente seja compartilhada no Estado de Direito Ambiental, na maioria das vezes, pela falta de consciência, a responsabilidade principal acaba recaindo apenas no Estado, cabendo a ele servir de exemplo, numa tentativa de despertar o interesse e a consciência da coletividade.

Um passo importante rumo à concretização de um Estado Ambiental é a participação popular, como observado nas palavras de Canotilho $(1999$, p. 17) que afirma que essa "nova dimensão do Estado pressupõe o diálogo democrático, exige instrumentos de participação, postula o princípio da cooperação com a sociedade civil".

De acordo com Fiorillo (2013), a participação constitui um dos elementos do Estado Social de Direito, ou Estado Ambiental de Direito, e para que ela seja efetivada são necessários dois elementos fundamentais que devem ser trabalhados em conjunto: a informação e a educação ambiental. Segundo o autor, a informação ambiental encontra respaldo legal nos Arts. 6으, § 3ำ, e 10 da Política Nacional do Meio Ambiente e a educação ambiental no Art. $225, \S 1$, VI, da Constituição Federal: "alguns princípios do direito ambiental constitucional se interpenetram, de modo a estabelecer uma interdependência. [...] a educação ambiental é efetivada mediante a informação ambiental, que é expressamente abraçada pela Constituição" (FIORILLO, 2013, p. 127).

Conforme Manzano (2008), para que a participação popular seja efetiva nas causas ambientais, é primordial a disponibilização de informações: 
Artigo | Estado e meio ambiente: como concretizar um Estado de Direito Ambiental? (GOMES, Chaiane Ferrazza; CEOLIN, Lisianne Sabedra; COLVERO, Ronaldo Bernardino)

El acesso a la información relevante es el elemento fundamental para permitir una participación realmente eficiente. Sin embargo, a pesar del consenso existente a la hora de vincular la eficácia de la participación a la existência de um flujo de información suficiente que garantisse que los ciudadanos puedan ser conscientes de como uma decisión puede afectar a sus interesses, la información a partir de la que puede funsarse la actividad participativa es, em mucha ocasiones, insuficiente, dificilmente acessible o sencillamente incompresible, de manera que el ciudadano deja estar em condicionas de participar de manera efectiva em el procedimento de toma de decisiones (MANZANO, 2008, p. 134-135).

Assim, para a participação popular ser efetiva é necessário que haja a disponibilização de informações, entretanto o que comumente acontece, segundo o autor, é que as informações disponibilizadas não são suficientes, de difícil acesso ou incompreensíveis para que o cidadão tenha condições de participar das decisões. Por isso, não é suficiente apenas disponibilizar informações, mas, sim, disponibilizar informações claras, suficientes e acessíveis ao entendimento de todos. Como aponta Machado (2016, p. 34), "quem estiver mal informado nem por isso estará impedido de participar, mas a qualidade de sua participação será prejudicada. A ignorância gera apatia ou inércia dos que teriam legitimidade para participar".

Verifica-se, então, que o acesso a informações e a educação ambiental são elementos essenciais para a efetivação da participação popular, entretanto ainda é necessário pensar em outro fator decisivo quando se pensa nessa prática: como estimular os cidadãos a participarem?

Pacheco (2015) defende que a participação popular deve ser estimulada através da criação de mecanismos efetivos para que os diversos setores da sociedade sejam ouvidos, informados e tutelados, de igual forma, contra os riscos conhecidos e desconhecidos. Para o autor, é através dessa perspectiva de abertura política, legitimado pela ampla participação social, que "se consubstanciará a visada justiça ambiental, que tenha como fio condutor a segurança e proteção dos titulares da norma ambiental" (PACHECO, 2015, p. 306).

Nesse sentido, Gohn (2014) traz alguns pressupostos gerais sobre a participação popular, embora eles não tivessem sido pensados exclusivamente para políticas públicas ambientais, podem contribuir para essa discussão, uma vez que trazem formas para contribuir com a efetividade e atratividade do processo participativo: 
Artigo | Estado e meio ambiente: como concretizar um Estado de Direito Ambiental? (GOMES, Chaiane Ferrazza; CEOLIN, Lisianne Sabedra; COLVERO, Ronaldo Bernardino)

a. Uma sociedade democrática só é possível via o caminho da participação dos indivíduos e grupos sociais organizados;

b. Não se muda a sociedade apenas com a participação no plano local, micro, mas é a partir do plano micro que se dá o processo de mudança e grupos sociais organizados;

c. É no plano local, especialmente num dado território, que se concentram as energias e forças sociais da comunidade, constituindo o poder local onde ocorrem as experiências, ele é a fonte do verdadeiro capital social, aquele que nasce e se alimenta da solidariedade como valor humano. O local gera capital social quando gera autoconfiança nos indivíduos de uma localidade, para que superem suas dificuldades. Gera, junto, com a solidariedade, coesão social, forças emancipatórias, fontes para mudanças e transformação social;

d. É no território local que se localizam as instituições importantes no cotidiano de vida da população, como as escolas, os postos de saúde etc. Mas o poder local de uma comunidade não existe a priori, tem que ser organizado, adensado em função de objetivos que respeitem as culturas e diversidades locais, que criem laços de pertencimento e identidade sóciocultural e política (GOHN, 2004, p. 24, grifo do autor).

Desses quatro pressupostos, pode-se extrair que a participação popular fortalece-se através de uma sociedade organizada e com enfoque no plano local. Pois, como coloca a autora, embora a participação apenas em âmbito local não mude a sociedade, essa participação pode ser um agente embrionário de uma transformação social maior. Além disso, Gohn (2004) afirma que é no plano local onde estão concentradas as energias e forças sociais da comunidade, pois é onde ocorrem as experiências, as quais são fonte de capital social. Entretanto, o plano local só gerará esse capital social na medida em que ele gerar autoconfiança dos indivíduos de uma localidade, quando isso acontece, gera solidariedade, coesão social, forças emancipatórias, as quais são fontes para mudanças e transformações sociais. Frente a isso, surge a seguinte questão: como gerar autoconfiança nos indivíduos?

Um estudo sobre o processo de Orçamento Participativo de Porto Alegre e Belo Horizonte demonstrou, em relação as suas características, que a participação está "diretamente ligada à credibilidade do processo como forma de deliberação pública. A participação no OP cumpre o papel de assegurar a publicidade na forma deliberativa e o acesso público à informação e à deliberação sobre a distribuição de materiais" 
Artigo | Estado e meio ambiente: como concretizar um Estado de Direito Ambiental? (GOMES, Chaiane Ferrazza; CEOLIN, Lisianne Sabedra; COLVERO, Ronaldo Bernardino)

(SANTOS; AVRITZER, 2009, p. 583). Desse modo, o autor refere-se que a assiduidade e o número expressivo de cidadãos que participam do OP em duas capitais brasileiras estão relacionados ao poder deliberativo que lhe são conferidos, sendo que isso se dá não apenas através do poder de decidir, mas também de ter acesso a informações relacionadas a essas deliberações.

Entende-se, então, que o fato de permitir a participação de indivíduos em reuniões ou audiências para tratar de assuntos governamentais de matéria ambiental por si só não garante uma participação popular efetiva, pois é necessário que seja conferido poder decisório aos membros, além de um retorno em relação às suas deliberações. Nesse sentido, Gohn (2014) defende que a participação "deve ser ativa e considerar a experiência de cada cidadão que nela se insere e não tratá-los como corpos amorfos a serem enquadrados em estruturas prévias, num modelo pragmatista" (GOHN, 2004, p. 24). Isto é, os cidadãos devem ser tratados como sujeitos de experiências e vivências que podem ser úteis para contribuir com o processo deliberativo e não apenas como um simples número compondo uma instituição participativa.

Além disso, é necessário que haja um estímulo para que os indivíduos possam se sentir motivados a participar e compartilhar suas vivências em instituições participativas da área ambiental. Nesse sentido, Melo (2016) afirma que a aplicação dos princípios da comunidade indagante ${ }^{6}$ pode ser uma opção interessante rumo à efetivação da participação popular nas questões ambientais na medida em que, primeiramente, é criado um contexto permeado pelo acolhimento, colaboração e confiança entre os membros, no qual todos possam sentir-se a vontade e motivados ao diálogo e, principalmente, possam sentir-se sujeitos atuantes imbuídos da capacidade de ouvir e ser ouvidos.

Segundo a autora, esse princípio foi construído a partir de estudos que apontaram que a ordem em um sistema social complexo e turbulento apenas pode ser obtida através de uma comunidade indagante. Esses estudos concluíram o seguinte:

\footnotetext{
${ }^{6}$ Segundo Melo (2016, p. 252), os princípios da comunidade indagante originaram-se no início da década de 70, a partir de estudos sobre as dinâmicas de grupos em ambientes complexos junto ao Tavistock Istitute of Human Relations de Londres e Group Dynamics Laboratory do MIT de Boston.
} 
Artigo | Estado e meio ambiente: como concretizar um Estado de Direito Ambiental? (GOMES, Chaiane Ferrazza; CEOLIN, Lisianne Sabedra; COLVERO, Ronaldo Bernardino)

[...] para formar uma "comunidade indagante" é necessário garantir uma situação em que: a relação dialógica e acolhedora deixe as pessoas à vontade; compartilhe-se um quadro de interesses e ideias comuns, suficientemente amplo para tornar inofensivas as áreas de desacordo (que serão depois enfrentadas, mas em um clima de colaboração e de confiança recíproca); cada participante sinta-se e seja visto pelos outros com um coprotagonista (MELO, 2016, p. 252).

Entretanto, Melo (2012, p. 164-165) afirma que o principal obstáculo dessa metodologia é "que mudar as formas de governo implica mudar as formas de autoridade que dão sustentação ao governo, ou seja, mudar hábitos profundamente radicados relativos ao sentido que o sujeito tem de si mesmo e dos outros". Isso pode ser constatado, segundo a autora, pela inicial atitude de engajamento dos participantes perante a experimentação seguida pela atitude de desleixo e abandono das práticas, retornando-os aos antigos hábitos.

No âmbito das políticas públicas para a sustentabilidade ambiental, aponta Melo (2012), isso também acontece e, portanto, sendo necessária uma mudança de hábitos cotidianos dos governos e dos cidadãos:

[...] iniciativas que podem ser mais simples ou ambiciosas, porém igualmente necessárias, visto que uma melhor qualidade de vida no planeta envolve ações que vão desde a participação nos Summits e nas Conferências internacionais para o meio ambiente, até a decisão de reduzir as luzes acesas no escritório ou em casa, reduzir a temperatura do ar condicionado, optar por um carro menos elegante mas mais econômico ou mesmo escolher a bicicleta, separar o lixo, reusar, reciclar. Trata-se de transformações necessárias em todos os níveis, desde a decisão pelo plano energético do país, o urbanismo da cidade, o transporte usado para ir ao trabalho, a merenda da escola, até as escolhas de consumo e do tempo livre, que podem privilegiar atividades mais saudáveis e um modelo de turismo ambientalmente sustentável (MELO, 2012, p. 165).

Verifica-se que quando se fala em mudanças de hábitos, não se refere apenas a grandes mudanças ou acontecimentos, mas também a atitudes corriqueiras do dia a dia que devem virar hábito, como economizar energia elétrica e separar, reduzir e reciclar o próprio lixo, que estão ao alcance da maioria dos indivíduos. Pequenos e grandes atos que devem partir de todos os níveis, desde o cidadão comum até os altos escalões 
Artigo | Estado e meio ambiente: como concretizar um Estado de Direito Ambiental? (GOMES, Chaiane Ferrazza; CEOLIN, Lisianne Sabedra; COLVERO, Ronaldo Bernardino)

governamentais. Esse seria um passo importante em direção ao princípio da comunidade indagante.

Santos e Avritzer (2009) defendem, a partir de seus estudos, três teses para o fortalecimento da democracia participativa:

1 - Pelo fortalecimento da demodiversidade: implica em reconhecer que não existe motivo para reconhecer apenas uma forma de democracia, já que, pelo contrário, "o multiculturalismo e as experiências recentes de participação apontam no sentido da deliberação pública ampliada e o adensamento da participação". Os autores defendem que o primeiro elemento importante da democracia participativa seria 0 "aprofundamento dos casos nos quais o sistema político abre mão de prerrogativas de decisão em favor de instâncias participativas".

2 - Fortalecimento da articulação contra-hegemônica entre o local e o global; democracias novas e fracas precisam do apoio de atores democráticos transnacionais, porém, experiências alternativas locais precisam ser expandidas para que se apresentem como alternativas ao modelo hegemônico: "a passagem do contra-hegemônico do plano local para o global é fundamental para o fortalecimento da democracia participativa".

3 - Ampliação do experimentalismo democrático - os autores perceberam através de suas pesquisas que as experiências bem-sucedidas se originaram de novas gramáticas sociais nas quais o formato da participação foi sendo adquirido experimentalmente: "é necessário para a pluralização cultural, racial e distributiva da democracia que se multipliquem experimentos em todas essas direções" (SANTOS; AVRITZER, 2009, p. 77, grifo do autor).

Sendo assim, da primeira tese extrai-se que o fortalecimento da democracia participativa pode dar-se através de uma adaptação à realidade cultural e étnica de cada grupo, na qual a democracia adquira um modelo condizente com os atores envolvidos, sendo delineada e sendo constantemente adaptada de forma a otimizar o processo participativo democrático.

A segunda tese dos autores vai ao encontro do que Gohn (2004) defende na medida em que eles afirmam que os exemplos bem-sucedidos de democracia participativa local precisam expandir-se para o plano global para que sirvam de inspiração para outras comunidades locais, sendo isso um fator importante rumo ao fortalecimento da democracia participativa. 
Artigo | Estado e meio ambiente: como concretizar um Estado de Direito Ambiental? (GOMES, Chaiane Ferrazza; CEOLIN, Lisianne Sabedra; COLVERO, Ronaldo Bernardino)

Da terceira e última tese de Santos e Avritzer (2009) pode-se compreender que é necessário adaptar o formato de participação conforme as experiências em cada local, isto é, nem sempre um dado modelo vai ser efetivo em uma dada localidade, já que cada uma possui suas peculiaridades, suas experiências e um conjunto de indivíduos diferentes. Dessa forma, sendo necessário ir adaptando o processo de participação a tais fatores de modo que a preocupação principal seja ter um processo participativo efetivo sem, necessariamente, prender-se a um modelo democrático engessado.

Desse modo, a partir das contribuições trazidas para o debate teórico, construiuse um quadro para melhor visualizar que fatores são importantes para que haja uma participação popular efetiva e mais abrangente possível nas causas ambientais:

Quadro 1 - Participação efetiva x Pseudoparticipação

\begin{tabular}{|c|c|}
\hline PARTICIPAÇÃO EFETIVA & PSEUDOPARTICIPAÇÃO \\
\hline $\begin{array}{l}\text { Informações claras, suficientes e acessíveis ao } \\
\text { entendimento de todos. }\end{array}$ & $\begin{array}{l}\text { Informações insuficientes, de difícil acesso ou } \\
\text { incompreensíveis pela maioria dos cidadãos. }\end{array}$ \\
\hline Grupos sociais organizados; & Sociedade civil aleatória e desorganizada; \\
\hline $\begin{array}{l}\text { Local como fonte de valor social e inspiração para } \\
\text { o plano global. }\end{array}$ & $\begin{array}{l}\text { Desvalorização e descrença do poder de } \\
\text { participação local; }\end{array}$ \\
\hline $\begin{array}{l}\text { Indivíduos como sujeitos de experiências e } \\
\text { vivências; }\end{array}$ & Indivíduos como "corpos amorfos". \\
\hline $\begin{array}{l}\text { Criação de um ambiente de acolhimento, } \\
\text { colaboração e confiança. }\end{array}$ & Ambiente hostil e intimidador. \\
\hline Indivíduos com poder deliberativo. & $\begin{array}{l}\text { Indivíduos como números integrantes de uma } \\
\text { estrutura participativa pragmática. }\end{array}$ \\
\hline $\begin{array}{l}\text { Estruturas democráticas adaptadas } \\
\text { multiculturalismo. }\end{array}$ & Estruturas democráticas rígidas. \\
\hline
\end{tabular}

Fonte: Elaborado pela autora (2019), baseado em Manzano (2008), Gohn (2004), Melo (2016), Avritzer (2008) e Santos e Avritzer (2009).

\section{Considerações finais}

A Constituição de 1988 pode ser considerada um divisor de águas no que diz respeito à preocupação ambiental, pois a partir de sua promulgação um meio ambiente sadio e equilibrado passou a ser um direito fundamental, cabendo ao Estado, juntamente com a coletividade, a sua tutela e o dever de preservá-lo para as futuras 
Artigo | Estado e meio ambiente: como concretizar um Estado de Direito Ambiental? (GOMES, Chaiane Ferrazza; CEOLIN, Lisianne Sabedra; COLVERO, Ronaldo Bernardino)

gerações. Essa construção jurídico-estatal, reconhecida como Estado de Direito Ambiental, pressupõe um Estado e uma coletividade preocupados e engajados com a proteção e o uso sustentável dos recursos naturais perante à mercantilização. Trata-se de uma construção teórica e sua concretização passa a ser, mais do que nunca, o grande desafio do século XXI, na medida em que os recursos naturais são finitos enquanto que a exploração dos mesmos cresce exponencialmente juntamente com o aumento do consumismo. E, ao lado disso, ainda há um baixo engajamento da sociedade quando se trata de causas ambientais.

Porém, ao contrário do que se pode pensar, sua construção depende, num primeiro momento, de pequenas e simples ações considerando a dimensão da causa. Percebeu-se que para um Estado Ambiental ser efetivado na prática é necessária, primeiramente, a tomada de consciência coletiva que implica em mudança de comportamento, tornando habituais ações e comportamentos como apagar as luzes quando não estão sendo usadas e separar, reduzir e reciclar o próprio lixo, as quais estão ao alcance da maioria dos indivíduos. Pequenos atos que, coletivamente, tornam-se grandes ações. Ter atitudes sustentáveis requer a criação de uma cultura sustentável a qual é criada através da educação ambiental, que também cabe ao Estado promovê-la.

Somado a isso, um fator imprescindível no alcance de um Estado efetivamente ambiental é a participação popular, a qual exige a contrapartida do Estado, cabendo a esse ofertar mecanismos efetivos de participação, e da sociedade, a qual deve organizarse em grupos sociais para angariar força. Contatou-se que um possível caminho a ser trilhado para atingir uma participação eficaz é enfocar no plano local, fornecendo poder deliberativo aos indivíduos, tratando-os como sujeitos de vivências e experiências e oferecendo-os um ambiente acolhedor e não intimador. Isto é, as pessoas devem sentirse à vontade, motivadas e valorizadas, para tanto deve ser oferecido uma estrutura democrática adaptável as suas culturas e realidades diárias, caso contrário está fadada a uma pseudo-participação. Para os cidadãos, além da iniciativa de juntar-se a um grupo social, cabe também cobrar esses mecanismos de participação condizentes com suas realidades locais.

Portanto, por mais complexa que aparente ser, ainda sim é possível a construção de um Estado de Direito Ambiental e para sua efetivação envolve um processo lento de conscientização de cidadãos e governantes, de educação ambiental e da promoção de 
Artigo | Estado e meio ambiente: como concretizar um Estado de Direito Ambiental? (GOMES, Chaiane Ferrazza; CEOLIN, Lisianne Sabedra; COLVERO, Ronaldo Bernardino)

uma participação popular efetiva. Como afirma Leite (2010, p. 169), o Estado de Direito Ambiental é "por si só, um conceito abrangente, pois tem incidência necessária na análise da Sociedade e da Política, não se restringindo ao Direito".

\section{Referências}

AVRITZER, L. Instituições participativas e desenho institucional: algumas considerações sobre a variação da participação do Brasil democrático. Opinião Pública, Campinas, vol. 14, n. 1, jun. 2008, p. 43- 64. Disponível em: <http://www.scielo.br/pdf/op/v14n1/02.pdf >. Acesso em: 09 nov. 2018.

BECK, U. Sociedade de risco: rumo a uma outra modernidade. 2. ed. São Paulo: 34, 2011.

BENJAMIN, A. H. Constitucionalização do ambiente e ecologização da constituição brasileira. In: CANOTILHO, J. J. G.; LEITE, J. R. M. (org.). Direito constitucional ambiental brasileiro. 3. ed. rev. São Paulo: Saraiva, 2010.

BERTÉ, R. Gestão socioambiental no Brasil: uma análise ecocêntrica. Curitiba: Intersaberes, 2013.

BRASIL. Constituição da República Federativa do Brasil de 1967, de 24 de janeiro

de $1967 . \quad$ Brasília, $1967 . \quad$ Disponível em:
<http://www.planalto.gov.br/CCivil_03/Constituicao/Constituicao67.htm>. Acesso em: 10 ago. 2018.

BRASIL. Lei 6.938, de 31 de agosto de 1981. Dispõe sobre a Política Nacional do Meio Ambiente, seus fins e mecanismos de formulação e aplicação, e dá outras providências. Brasil, $1981 . \quad$ Disponível em: <http://www.planalto.gov.br/ccivil 03/Leis/L6938.htm. >. Acesso em: 8 agos. 2018.

BRASIL. Constituição da República Federativa do Brasil de 1988, de 05 de outubro de $1988 . \quad$ Brasília, 1988.1 Disponível <http://forumeja.org.br/sites/forumeja.org.br/files/constituicaofederal1988.pdf> . Acesso em: 14 set. 2017.

CANOTILHO, J. J. G. Estado de Direito. Lisboa: Fundação Mário Soares, 1999.

CÂMARA, L. A.; OLIVEIRA, C. Breves impressões sobre a legitimidade da tutela penal do meio ambiente. In: GALLI, A. (Coord.). Direito socioambiental: homenagem a Vladimir Passos. Curitiba: Juruá, 2011.

FIORILLO, C. A. P. Curso de direito ambiental brasileiro. 14. ed. São Paulo: Saraiva, 2013.

FREITAS, V. P. de. Direito administrativo e meio ambiente. 4. ed. Curitiba: Juruá, 2010. 
Artigo | Estado e meio ambiente: como concretizar um Estado de Direito Ambiental? (GOMES, Chaiane Ferrazza; CEOLIN, Lisianne Sabedra; COLVERO, Ronaldo Bernardino)

GOHN, M. G. Empoderamento e participação da comunidade em políticas sociais. Saúde e Sociedade, v. 13, n. 2, p. 20-31, mai./agos. 2014. Disponível em: http://www.scielo.br/pdf/sausoc/v13n2/03.pdf. Acesso em: 27 out. 2018.

LEITE, J. R. M.. Sociedade de risco e Estado. In: CANOTILHO, J. J. G.; LEITE, J. R. M. (Orgs.). Direito constitucional ambiental brasileiro. 3. ed. rev. São Paulo: Saraiva, 2010.

MANZANO, J. J. El fundamento constitucional de los derechos de participación em materia de medio ambiente y su desarrollo em la ley 27/2006. In: SOLÉ, A. (Org.). Acesso a la información, participación pública y acceso a la justicia em materia de medio ambiente: diez años del Convenio de Aahus. Barcelona: Ed. Atelier, 2008.

MELO, M. P. Desenvolvimento sustentável: das Declarações internacionais à planificação estratégica e governance local. In: WOLKMER, M. de F. S.; MELO, M. P. Crise ambiental, direitos à agua e sustentabilidade: visões multidisciplinares. Caxias do Sul, RS: $\quad 2012 . \quad$ Disponível em: <https://www.ucs.br/site/midia/arquivos/CRISE_AMBIENTAL_EDUCS_E_BOOK.pdf>. Acesso em: 07 ago. 2018.

MELO, M. P. Desenvolvimento sustentável: das declarações internacionais à governance local. Revista Internacional de Direito Ambiental, ano v, n. 15, set./dez. 2016. Caxias do Sul, RS: Plenum, 2016.

MURO JR., A. Aspectos legais da poluição do ar. Revista Internacional de Direito Ambiental, ano v, n. 15, set./dez. 2016. Caxias do Sul, RS: Plenum, 2016.

NUNES JÚNIOR, A. T. O Estado ambiental de Direito. Revista Jus Navigandi, Teresina, ano $10, \underline{n}$. $589,17 \mathrm{fev} .2005$.

Disponível em: <https://jus.com.br/artigos/6340>. Acesso em: 9 ago. 2018.

O'DONNELL, G. Democracia, agência e estado: teoria com intenção comparativa. São Paulo: Paz e Terra, 2011.

PACHECO, C. G. As desventuras de um Estado de Direito Ambiental. Revista de Informação Legislativa, ano 52, n. 205, p. 297-317, jan./fev. 2015. Disponível em: <https://www12.senado.leg.br/ril/edicoes/52/205/ril v52 n205 p297.pdf >. Acesso em: 13 nov. 2019.

PIOVESAN, F; FACHIN, M. G. Direitos humanos e meio ambiente. In: In: GALLI, Alessandra (Coord.). Direito socioambiental: homenagem a Vladimir Passos. Curitiba: Juruá, 2011.

PUREZA, J. M.; FRADE, C. Direito do ambiente. Coimbra: Faculdade de Economia da Universidade de Coimbra, 1998.

RODRIGUES, J. E; FERNANDES, V.; PHILIPPI JR., A. Política e gestão ambiental no Brasil. In: GALLI, A. (Coord.). Direito socioambiental: homenagem a Vladimir Passos. Curitiba: Juruá, 2011.

SACCOL, A. P. A concepção de Estado no pensamento de Durkheim: Lições de sociologia. Revista Eletrônica dos Pós Graduandos em Sociologia Política da UFSC, v. 8, n. 1 , jan./ jul., 2012 Disponível em: 
Artigo | Estado e meio ambiente: como concretizar um Estado de Direito Ambiental? (GOMES, Chaiane Ferrazza; CEOLIN, Lisianne Sabedra; COLVERO, Ronaldo Bernardino)

<https://periodicos.ufsc.br/index.php/emtese/article/viewFile/18065023.2012v9n1p9 6/23490>. Acesso em: 9 ago. 2018.

SANTOS, B. S. S.; AVRITZER, L. Para ampliar o cânone democrático. In: SANTOS, Boaventura de Souza Santos (org.). Democratizar a democracia: os caminhos da democracia participativa. 4. ed. Civilização Brasileira, 2009.

SARLET, I. W.; FENSTERSEIFER, T. Estado socioambiental e mínimo existencial (ecológico?): algumas aproximações. In: SARLET, I. W. (org.). Estado socioambiental e direitos fundamentais. Porto Alegre: Livraria do Advogado, 2010.

SCHIERA, P. Estado Moderno. In: BOBBIO, N.; MATTEUCI, N.; PASQUINO, G. Dicionário de política. v. 1. 11. ed. Brasília, DF: UnB, 1998.

SIRVINSKAS, L. P. Manual de direito ambiental. 4. ed. São Paulo: Saraiva, 2006.

SILVA, J. A. Direito ambiental constitucional. 2. ed. São Paulo: Malheiros, 1998.

WEBER, M. Economia e sociedade: fundamentos da sociologia compreensiva. v. 1. Brasília, DF: Editora Universidade de Brasília: São Paulo: Imprensa Oficial do Estado de São Paulo, 1999. 